\title{
DÜBLIN
}

Technological University Dublin

ARROW@TU Dublin

\section{PID compensation of time delayed processes 1998-2002: a survey}

Aidan O'Dwyer

Technological University Dublin, aidan.odwyer@tudublin.ie

Follow this and additional works at: https://arrow.tudublin.ie/engscheleart

Part of the Controls and Control Theory Commons

\section{Recommended Citation}

O'Dwyer, Aidan :PID compensation of time delayed processes 1998-2002: a survey. Proceedings of the American Control Conference, pp. 1494-1499, Denver, Colorado, USA, June. doi:10.21427/dkx2-9503

This Conference Paper is brought to you for free and open access by the School of Electrical and Electronic Engineering at ARROW@TU Dublin. It has been accepted for inclusion in Conference papers by an authorized administrator of ARROW@TU Dublin. For more information, please contact arrow.admin@tudublin.ie, aisling.coyne@tudublin.ie, gerard.connolly@tudublin.ie.

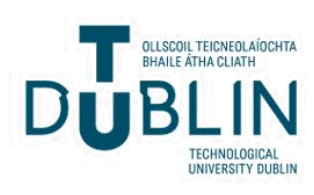




\title{
PID compensation of time delayed processes 1998-2002: a survey
}

\author{
Aidan O'Dwyer \\ School of Control Systems and Electrical Engineering, \\ Dublin Institute of Technology, Kevin St., Dublin 8, Ireland \\ E-mail: aidan.odwyer@dit.ie
}

\begin{abstract}
A time delay may be defined as the time interval between the start of an event at one point in a system and its resulting action at another point in the system. Delays are also known as transport lags or dead times; they arise in physical, chemical, biological and economic systems, as well as in the process of measurement and computation. Methods for the compensation of time delayed processes may be broadly divided into proportional integral derivative (PID) based controllers, in which the controller parameters are adapted to the controller structure, and structurally optimised controllers, in which the controller structure and parameters are adapted optimally to the structure and parameters of the process model. The purpose of this paper is to extract the essence of the developments in design, tuning and implementation of PID controllers for delayed processes over the five years 1998-2002, concentrating on journal publications. The paper will provide a framework against which the literature may be viewed.
\end{abstract}

\section{INTRODUCTION}

The use of the PID controller is ubiquitous in industry; it has been stated, for example, that in process control applications, more than $95 \%$ of the controllers are of PID type (Astrom and Hagglund 1995). Despite the development of a large number of alternative control algorithms over the past four decades, and the fact that PID controllers have been used widely in industry for almost sixty years, their popularity is growing; eighty-three publications on the control of delayed processes using PID controllers have been recorded by the author in the year 2000, for example (O'Dwyer 2003a). However, Ender (1993) maintains that, in his testing of thousands of control loops in hundreds of plants, it has been found that more than $30 \%$ of installed controllers are operating in manual mode and $65 \%$ of loops operating in automatic mode produce less variance in manual than in automatic (i.e. the automatic controllers are poorly tuned); this is rather sobering, considering the wealth of information available in the literature for determining controller parameters. Table 1 is instructive in this regard.

Due to space considerations, this paper will provide an overview of continuous time PID compensation techniques, proposed since 1998, for SISO processes with time delay. Other reviews are recommended to the interested reader (Seborg et al. 1986; Bueno et al. 1991; Fisher 1991; Koivo and Tanttu 1991; Astrom et al. 1993; Astrom et al. 1995; Astrom 1996; Chen 1996; Unar et al. 1996; Gorez 1997; Tan et al. 1999; Astrom and Hagglund 2000a; Lelic and Gajic 2000; Cominos and Munro 2002; Hang et al. 2002; O’Dwyer 2003a,b).

Table 1: Control of delayed processes using PID controllers: publications by date (O’Dwyer, 2003a)

\begin{tabular}{|c|c|c|}
\hline Year & $\begin{array}{c}\text { Journal } \\
\text { articles }\end{array}$ & $\begin{array}{c}\text { Total } \\
\text { publications }\end{array}$ \\
\hline $1942-1952$ & 4 & 4 \\
\hline $1953-1962$ & 4 & 5 \\
\hline $1963-1972$ & 13 & 16 \\
\hline $1973-1982$ & 7 & 14 \\
\hline $1983-1992$ & 61 & 111 \\
\hline $1993-2002$ & 229 & 384 \\
\hline & & \\
\hline $1993-1997$ & 100 & 159 \\
\hline $1998-2002$ & 129 & 225 \\
\hline
\end{tabular}

The PID controller may be implemented in continuous or discrete time, in a number of controller structures. The ideal continuous time PID controller is expressed in Laplace form as follows:

$$
\mathrm{G}_{\mathrm{c}}(\mathrm{s})=\mathrm{K}_{\mathrm{c}}\left(1+\frac{1}{\mathrm{~T}_{\mathrm{i}} \mathrm{s}}+\mathrm{T}_{\mathrm{d}} \mathrm{s}\right)
$$

with $\mathrm{K}_{\mathrm{c}}=$ proportional gain, $\mathrm{T}_{\mathrm{i}}=$ integral time constant and $\mathrm{T}_{\mathrm{d}}=$ derivative time constant. If $\mathrm{T}_{\mathrm{i}}=\infty$ and $\mathrm{T}_{\mathrm{d}}=0$ (i.e. $\mathrm{P}$ control), then the closed loop measured value will always be less than the desired value for processes without an integrator term, as a positive error is necessary to keep the measured value constant, and less than the desired value. The introduction of integral action facilitates the achievement of equality between the measured value and the desired value, as a constant error produces an increasing controller output. The introduction of derivative action means that changes in the desired value may be anticipated, and thus an appropriate correction may be added prior to the actual change. Thus, in simplified terms, the PID controller allows contributions from present, past and future controller inputs.

In many cases, the design of PID controllers for delayed processes are based on methods that were originally used for the controller design of delay-free processes. 
However, there is general agreement that PID controllers are not well suited for the control of dominant delay processes. It has been suggested that the PID implementation is recommended for the control of processes of low to medium order, with small delays, when controller parameter setting must be done using tuning rules and when controller synthesis may be performed a number of times (Isermann 1989).

\section{THE SPECIFICATION OF PI OR PID CONTROLLER PARAMETERS}

\subsection{Iterative Methods}

The choice of appropriate compensator parameters may be achieved experimentally e.g. by manual tuning. However, such an approach is time consuming and the process typically has to be driven to its stability limit. Alternatively, a graphical or analytical approach to controller tuning may be done in either the time or frequency domains. The time domain design is done using root locus diagrams; it is, however, questionable that a delayed process would be sufficiently well modelled by the necessary second order model. The frequency domain design is typically done using Bode plots to achieve a desired phase margin. Iterative methods for controller design provide a first approximation to desirable controller parameters.

\subsection{Tuning Rules}

Process reaction curve tuning rules are based on calculating the controller parameters, from the model parameters determined from the open loop process step response. This method was originally suggested by Ziegler and Nichols (1942), who modelled the SISO process by a first order lag plus delay (FOLPD) model, estimated the model parameters using a tangent and point method and defined tuning parameters for P, PI and PID controllers. Other process reaction curve tuning rules of this type are also described, sometimes in graphical form, to control processes modelled by a FOLPD model (Shinskey 2001) or an integral plus delay (IPD) model (Hay 1998). The advantages of such tuning strategies are that only a single experimental test is necessary, a trial and error procedure is not required and the controller settings are easily calculated; however, it is difficult to calculate an accurate and parsimonious process model, load changes may occur during the test which may distort the test results and a large step input may be necessary to achieve a good signal to noise ratio.

Performance (or optimisation) criteria, such as the minimisation of the integral of absolute error in a closed loop environment, may be used to determine a unique set of controller parameter values. Tuning rules have been described, sometimes in graphical form, to optimise either the regulator response or the servo response, of a compensated SISO process, modelled in stable or unstable FOLPD form (Wilton 1999; Majhi and Atherton 2000; Visioli 2001a; Shen 2002), IPD form (Visioli 2001a), stable or unstable second order system plus delay (SOSPD) form (Wilton 1999; Kwak et al. 2000) or more general form (Shen 2000). Tuning rules to achieve specified servo and regulator responses simultaneously are also described (Tan et al. 1998; Yang and Shao 2000a).

Ultimate cycle tuning rules are calculated from the controller gain and oscillation period recorded at the ultimate frequency (i.e. the frequency at which marginal stability of the closed loop control system occurs). The first such tuning method was defined by Ziegler and Nichols (1942) for the tuning of P, PI and PID controller parameters of a process that may or may not include a delay. The tuning rules implicitly build an adequate frequency domain stability margin into the compensated system. Such tuning rules, to compensate delayed processes by either minimising a performance criterion, or achieving a specified gain and/or phase margin, are discussed when the SISO process is modelled in IPD form (Kookos et al. 1999), or stable or unstable SOSPD form (Luyben 2000). Alternatively, ultimate cycle tuning rules, and modifications of the rules in which the proportional gain is set up to give a closed loop transient response decay ratio of 0.25 , or a phase lag of $135^{\circ}$, may compensate general, possibly delayed, stable or unstable processes (Hay 1998; Tan et al. 1999; Yu 1999; Prashanti and Chidambaram 2000; Tan et al. 2001; Robbins, 2002a), sometimes to achieve either a specified gain and/or phase margin (Prashanti and Chidambaram 2000; Tan et al. 2001) or a specified closed loop response (Vrancic et al. 1999, 2001). The controller settings are easily calculated; however, the system must generally be destabilised under proportional control, the empirical nature of the method means that uniform performance is not achieved in general, several trials must typically be made to determine the ultimate gain, the resulting process upsets may be detrimental to product quality, there is a danger of misinterpreting a limit cycle as representing the stability limit and the amplitude of the process variable signal may be so great that the experiment may not be carried out for cost or safety considerations.

Direct synthesis tuning rules result in a controller that facilitates a specified closed loop response. These methods include pole placement strategies and frequency domain techniques, such as gain margin and/or phase margin specification methods. Pole placement strategies are described to compensate SISO processes modelled in stable or unstable FOLPD form (Bi et al. 1999; Chien et al. 1999; Huang et al. 2000; Zhang and Xu 2000; Mann et al. 2001b; Chen and Seborg, 2002), IPD form (Chen et al. 1999; Chien et al. 1999a; Chen and Seborg, 2002), first order lag plus integral plus delay (FOLIPD) form (Chen and Seborg, 2002) or SOSPD form (Wang et al. 1999a; Bi et al. 2000; Chen and Seborg, 2002). Frequency domain based tuning 
rules are also described, for processes modelled in stable or unstable FOLPD form (Ho et al. 1998; Ho and Xu 1998; Chen et al. 1999a; Wang and Cai 2002), stable or unstable SOSPD form (Ho and Xu 1998; Huang et al. 2000; Wang et al. 2001a), IPD form (Poulin and Pomerleau 1999; Cheng and Yu 2000; Kristiansson and Lennartson 2002), FOLIPD form (Kristiansson and Lennartson 2002; Wang and Cai 2002) or more general form (Yang and Shao 2000b, Kristiansson and Lennartson 2002; Tang et al. 2002).

The presence of unmodelled process dynamics demands a robust design approach. The Internal Model Control (IMC) design procedure, which allows uncertainty on the process parameters to be specified, may be used to design appropriate PI and PID controllers; other robust strategies may also be used to design such controllers. Processes may be modelled in stable or unstable FOLPD form (Alvarez-Ramirez et al. 1998; Lee et al. 1998; Chen et al. 1999b; Chun et al. 1999; Isaksson and Graebe 1999; Lee et al. 2000; Leva and Colombo 2000; Rivera and Jun 2000; Marchetti and Scali 2000; Ho et al. 2001; Luyben 2001; Zhong and Li 2002; Huang et al. 2002), IPD form (AlvarezRamirez et al. 1998; Zhang et al. 1999; Rivera and Jun 2000; Zhong and Li 2002) or stable and unstable SOSPD form (Lee et al. 1998; Chen et al. 1999b; Rivera and Jun 2000; Zhong and Li 2002; Zhang and Xu 2002).

Tuning rules are easy to use, even in the absence of an accurate process model. These design methods are suitable for the achievement of a simple performance specification, for a compensated process with a nondominant delay. Comprehensive summaries of the tuning rule formulae are available (O'Dwyer 2003b). A summary of tuning rules published by year and medium is provided in Table 2; as this table shows, interest in the development of tuning rules is growing.

Table 2: Tuning rules - publications by date (O'Dwyer,

\begin{tabular}{|c|c|c|}
\hline \multicolumn{1}{|c|}{ Year } & $\begin{array}{c}\text { Journal } \\
\text { articles }\end{array}$ & $\begin{array}{c}\text { Total } \\
\text { publications }\end{array}$ \\
\hline $1942-1952$ & 4 & 4 \\
\hline $1953-1962$ & 4 & 4 \\
\hline $1963-1972$ & 7 & 9 \\
\hline $1973-1982$ & 5 & 8 \\
\hline $1983-1992$ & 21 & 38 \\
\hline $1992-2002$ & 99 & 160 \\
\hline & & \\
\hline $1992-1997$ & 46 & 72 \\
\hline $1998-2002$ & 53 & 88 \\
\hline
\end{tabular}

\subsection{Analytical Techniques}

Controller parameters may be determined using analytical techniques. Some methods minimise an appropriate performance index (Astrom et al. 1998; Ham and Kim 1998; Kookos et al. 1999; Liu and Daley 1999; Leva and Colombo 1999; He et al. 2000; Howell and Best
2000; Tan et al. 2000; Wang and Cluett 2000; Leva and Colombo 2001; Campi et al. 2002; Panagopoulos et al. 2002; Hwang and Hsiao 2002; Robbins, 2002b; Sung et al. 2002; Tan et al. 2002; Yang et al. 2002a). Alternatively, a direct synthesis strategy may be used to determine the controller parameters. Such strategies may be defined in the time domain, possibly by using pole placement (Atherton 1999; Daley and Liu 1999; Jung et al. 1999a, 1999b; Majhi and Atherton 1999; Jaguste and Agnihotri 2002) or in the frequency domain, possibly by specifying a desired gain and/or phase margin (Fung et al. 1998; Wang et al. 1999b, 1999c; Grassi et al. 2001; Seki et al. 2001; Crowe and Johnson 2002; Yang et al. 2002b).

Robust methods may be used to design analytically an appropriate PID controller (Huang and Wang 2001; Wang et al. 2001b; Ge et al. 2002). Finally, alternative design methods may be used to determine the controller parameters, such as fuzzy logic (Bandyopadhyay and Patranabis 1998, 2001; Blanchett et al. 2000; Xu et al. 1998, 2000; Li and Tso 1999, 2000; Mudi and Pal 1999; Visioli 1999, 2001b; Wang et al. 1999d; Tao and Taur 2000; Mann et al. 2001a), genetic algorithms (Cheng and Hwang 1998; Wang et al. 1999d) or neural networks (Huang et al. 1999; Sbarbaro et al. 2000; Shu and Pi 2000).

Analytical methods are suitable for the design of PI/PID controllers for non-dominant delay processes where there are well-defined performance requirements to be achieved.

\section{CONCLUSIONS}

Control academics and practitioners remain interested in the use of the PID controller to compensate processes with time delay. This paper provides a comprehensive summary of such compensation techniques that have appeared in relevant journals since 1998. It is the hope of the author that the paper will provide a convenient reference for application work. The work demonstrates that new design techniques have been accumulating, each claiming that it is the best suited for the application. In general, there is a lack of comparative analysis with other design techniques; associated with this is the lack of benchmark examples, at least until the recent suggestions of Astrom and Hagglund (2000b), for testing the different methods. The main priority for future research should be a critical analysis of available design techniques.

\section{REFERENCES}

Alvarez-Ramirez, J., A. Morales, and I. Cervantes. 1998. "Robust proportional-integral control", Industrial Engineering Chemistry Research, 37, 4740-4747.

Astrom, K.J., T. Hagglund, C.C. Hang and W.K. Ho. 1993. "Automatic tuning and adaptation for PID controllers - a survey", Control Engineering Practice, 1, 699-714.

Astrom, K.J., T.H. Lee, K.K. Tan and K.H. Johansson. 1995. "Recent advances in relay feedback methods - a survey", 
Proceedings of the IEEE International Conference on Systems, Man and Cybernetics, 3, 2616-2621.

Astrom, K.J. 1996. "Tuning and adaptation", Proceedings of the $13^{\text {th }}$ IFAC World Congress, Plenary Volume, 1-18.

Astrom, K.J., H. Panagopoulos, and T. Hagglund. 1998. "Design of PI controllers based on non-convex optimisation", Automatica, 34, 1998, pp. 585-601.

Astrom, K.J. and T. Hagglund. 1995. PID controllers: theory, design and tuning, Second Edition, Instrument Society of America.

Astrom, K.J. and T. Hagglund, T. 2000a. "The future of PID control", Preprints of the Proceedings of PID '00: IFAC Workshop on digital control, Terrassa, Spain, 19-30.

Astrom, K.J. and T. Hagglund, T. 2000b. "Benchmark systems for PID control", Preprints of the Proceedings of PID '00: IFAC Workshop on digital control, Terrassa, Spain, 181-182.

Atherton, D.P. 1999. "PID controller tuning", IEE Computing and Control Engineering Journal, April, 44-50.

Bandyopadhyay, R. and D. Patranabis. 1998. "A fuzzy logic based PI autotuner”, ISA Transactions, Vol. 37, 227-235.

Bandyopadhyay, R. and D. Patranabis. 2001. "A new autotuning algorithm for PID controllers using dead-beat format", ISA Transactions, 40, 255-266.

Bueno, S.S., R.M.C. De Keyser and G. Favier. 1991. "Auto-tuning and adaptive tuning of PID controllers", Journal A, 32, No. 1, 28-34.

Bi, Q., W.-J. Cai, E.-L. Lee, Q.-G. Wang, C.-C. Hang and Y. Zhang. 1999. "Robust identification of first-order plus deadtime model from step response", Control Engineering Practice, 7, No. 1, 71-77.

Bi, Q., W.-J. Cai, Q.-G. Wang, C.-C. Hang, E.-L. Lee, Y. Sun, K.D. Liu, Y. Zhang and B. Zou 2000. "Advanced controller auto-tuning and its application in HVAC systems", Control Engineering Practice, 8, No. 6, 633-644.

Blanchett, T.P., G.C. Kember and R. Dubay. 2000. "PID gain scheduling using fuzzy logic", ISA Transactions, 39, No. 2, 317-325.

Campi, M.C., A. Lecchini and S.M. Savaresi. 2002. "Virtual reference feedback tuning: a direct method for the design of feedback controllers", Automatica, 38, 1337-1346.

Chen, C.-L., S.-H. Hsu and H.-P. Huang. 1999a. "Tuning PI/PD controllers based on gain/phase margins and maximum closed loop magnitude", Journal of the Chinese Institute of Chemical Engineers, 30, No. 1, 23-29.

Chen, C.-L., H.-P. Huang and C.-T. Hsieh. 1999b. "Tuning of PI/PID controllers based on specification of maximum closedloop amplitude ratio", Journal of Chemical Engineering of Japan, 32, No. 6, 783-788.

Chen, D. and D.E. Seborg (2002). "PI/PID controller design based on direct synthesis and disturbance rejection", Industrial Engineering Chemistry Research, 41, 4807-4822.

Chen, G. 1996. "Conventional and fuzzy PID controllers: an overview", International Journal of Intelligent Control and Systems, 1, No. 2, 235-246.

Cheng, S.-L. and C. Hwang. 1998. "Designing PID controllers with a minimum IAE criterion by a differential evolution algorithm”, Chemical Engineering Communications, 170, 83115.

Cheng, Y.-C. and C.-C. Yu. 2000. "Nonlinear process control using multiple models: relay feedback approach", Industrial Engineering Chemistry Research, 39, No. 2, 420-431.

Chien, I.-L., H.-P. Huang and J.-C. Yang. 1999. "A simple multiloop tuning method for PID controllers with no proportional kick", Industrial Engineering Chemistry Research, 38, No. 4, 1456-1468.

Chun, D., J.Y. Choi and J. Lee. 1999. "Parallel compensation with a secondary measurement", Industrial Engineering Chemistry Research, 38, No. 4, 1575-1579.

Cominos, P. and N. Munro. 2002. "PID controllers: recent tuning methods and design to specification", IEE Proceedings Control Theory and Applications, 149, No. 1, 46-53.

Crowe, J. and M.A. Johnson. 2002. "Towards autonomous PI control satisfying classical robustness specifications", IEE Proceedings - Control Theory and Applications, 149, No. 1, 26-31.

Daley, S. and G.P. Liu. 1999. "Optimal PID tuning using direct search algorithms", IEE Computing and Control Engineering Journal, April, 51-56.

Ender, D.B. 1993. "Process control performance: not as good as you think", Control Engineering, September, 180-190.

Fisher, D.G. 1991. "Process control: an overview and personal perspective", The Canadian Journal of Chemical Engineering, 69, 5-26.

Fung, H.-W., Q.-G. Wang and T.-H. Lee. 1998. "PI tuning in terms of gain and phase margins", Automatica, 34, 1145-1149.

Ge, M., M.-S. Chiu and Q.-G. Wang. 2002. "Robust PID controller design via LMI approach", Journal of Process Control, 12, 3-13.

Gorez, R. 1997. "A survey of PID auto-tuning methods", Journal A, 38, 3-10.

Grassi, E., K.S. Tsakalis, S. Dash, S.V. Gaikwad, W. MacArthur and G. Stein. 2001. "Integrated system identification and PID controller tuning by frequency loop-shaping", IEEE Transactions on Control Systems Technology, 9, No. 2, 285293.

Ham, T.W. and Y.H. Kim. 1998. "Process identification using pulse response and proportional-integral-derivative controller tuning with combined guidelines", Industrial Engineering Chemistry Research, 37, 482-488.

Hang, C.C., K.J. Astrom and Q.G. Wang. 2002. "Relay feedback auto-tuning of process controllers - a tutorial review", Journal of Process Control, 12, 143-162.

Hay, J. 1998. Regeltechniek 1, Die Keure n.v., Brugge, Belgium, 197-198.

He, J.-B., Q.-G. Wang and T.-H. Lee. 2000. "PI/PID controller tuning via LQR approach", Chemical Engineering Science, 55, 2429-2439.

Ho, W.K., K.W. Lim and W. Xu. 1998. "Optimal gain and phase margin tuning for PID controllers", Automatica, 34, No. 8, 1009-1014.

Ho, W.K. and W. Xu. 1998. "PID tuning for unstable processes based on gain and phase-margin specifications", IEE Proceedings - Control Theory and Applications, 145, No. 5, 392-396.

Ho, W.K., T.H. Lee, H.P. Han and Y. Hong. 2001. "Self-tuning IMC-PID control with interval gain and phase margins assignment", IEEE Transactions on Control Systems Technology, 9, No. 3, 535-541.

Howell, M.N. and M.C. Best. 2000. "On-line PID tuning for engine idle-speed control using continuous action reinforcement learning automata", Control Engineering Practice, 8, 147-154.

Huang, C.-T., M.-Y. Lin and M.-C. Huang. 1999. "Tuning PID controllers for processes with inverse response using artificial neural networks", Journal of the Chinese Institute of Chemical Engineers, 30, No. 3, 223-232. 
Huang, H.-P., M.-W. Lee and C.-L. Chen. 2000. "Inverse-based design for a modified PID controller", Journal of the Chinese Institute of Chemical Engineers, 31, No. 3, 225-236.

Huang, H.-P., M.-L. Roan and J.-C. Jeng. 2002. "On-line adaptive tuning for PID controllers", IEE Proceedings - Control Theory and Applications, 149, No. 1, 60-67.

Huang, Y.J. and Y.-J. Wang. 2001. "Robust PID controller design for non-minimum phase time delay systems", ISA Transactions, 40, 31-39.

Hwang, C. and C.-Y. Hsiao. 2002. "Solution of a non-convex optimization arising in PI/PID control design", Automatica, 38, 1895-1904.

Isaksson, A.J. and S.F. Graebe. 1999. "Analytical PID parameter expressions for higher order systems", Automatica, 35, 11211130.

Isermann, R., Digital control systems Volume 1. Fundamentals, deterministic control, 2nd Revised Edition, Springer-Verlag, 1989.

Jaguste, D.N. and R.B. Agnihotri. 2002. "Rationalizing PID tuning with a model based approach", Hydrocarbon Processing, September, 59-64.

Jung, C.L., H.K. Song and J.C. Hyun. 1999a. "A new directsynthesis tuning method for PI-controllers", The Canadian Journal of Chemical Engineering, 77, 180-185.

Jung, C.L., H.K. Song and J.C. Hyun. 1999b. "A direct synthesis tuning method of unstable first-order-plus-time-delay processes", Journal of Process Control, 9, No. 3, 265-269.

Koivo, H.N. and J.T. Tanttu. 1991. "Tuning of PID controllers: survey of SISO and MIMO techniques", Proceedings of the IFAC Intelligent Tuning and Adaptive Control Symposium, Singapore, 75-80.

Kookos, I.K., A.I. Lygeros and K.G. Arvanitis. 1999. "On-line PI controller tuning for integrator/dead time processes", European Journal of Control, 5, 19-31.

Kristiansson, B. and B. Lennartson. 2002. "Robust and optimal tuning of PI and PID controllers", IEE Proceedings - Control Theory and Applications, 149, No. 1, 17-25.

Kwak, H.J., S.W. Sung and I.-B. Lee. 2000. "Stabilizability conditions and controller design for unstable processes", Transactions of the Institute of Chemical Engineers, 78, Part A, 549-556.

Lee, Y., S. Park, M. Lee and C. Brosilow. 1998. "PID controller tuning to obtain desired closed-loop responses for SI/SO systems", AIChE Journal, 44, 106-115.

Lee, Y., J. Lee and S. Park. 2000. "PID tuning for integrating and unstable processes with time delay", Chemical Engineering Science, 55, 3481-3493.

Lelic, M. and Z. Gajic. 2000. "A reference guide to PID controllers in the nineties", Preprints of the Proceedings of PID '00: IFAC Workshop on digital control, Terrassa, Spain, 73-82.

Leva, A. and A.M. Colombo. 1999. "Method for optimising setpoint weights in ISA-PID autotuners", IEE Proceedings Control Theory and Applications, 146, No. 2, 137-146.

Leva, A. and A.M. Colombo. 2000. "Estimating model mismatch overbounds for the robust autotuning of industrial regulators", Automatica, 26, 1855-1861.

Leva, A. and A.M. Colombo. 2001. "Implementation of a robust PID autotuner in a control design environment", Transactions of the Institute of Measurement and Control, 23, No. 1, 1-20.

Li, H.-X. and S.K. Tso. 1999. "Higher order fuzzy control structure for higher order or time-delay systems", IEEE Transactions on Fuzzy Systems, 7, No. 5, 540-552.
Li, H.-X. and S.K. Tso. 2000. "Quantitative design and analysis of fuzzy proportional-integral-derivative control - a step towards autotuning", International Journal of Systems Science, 31, No. 5, 545-553.

Liu, G.P. and S. Daley. 1999. "Optimal tuning PID controller design in the frequency domain with application to a rotary hydraulic system", Control Engineering Practice, 7, 821-830.

Luyben, W.L. 2000. "Tuning proportional-integral controllers for processes with both inverse response and deadtime", Industrial Engineering Chemistry Research, 39, No. 4, 973-976.

Luyben, W.L. 2001. "Effect of derivative algorithm and tuning selection on the PID control of dead-time processes", Industrial Engineering Chemistry Research, 40, 3605-3611.

Majhi, S. and D.P. Atherton. 1999. "Autotuning and controller design for processes with small time delays", IEE Proceedings - Control Theory and Applications, 146, No. 5, 415-425.

Majhi, S. and D.P. Atherton. 2000. "Online tuning of controllers for an unstable FOPDT process", IEE Proceedings - Control Theory and Applications, 147, No. 4, 421-427.

Mann, G.K.I, B.-G. Hu and R.G. Gosine. 2001a. "Two-level tuning of fuzzy PID controllers", IEEE Transactions on Systems, Man and Cybernetics - Part B: Cybernetics, 31, No. 2, 263-269.

Mann, G.K.I., B.-G. Hu and R.G. Gosine. 2001b. "Time-domain based design and analysis of new PID tuning rules", IEE Proceedings - Control Theory and Applications, 148, No. 3, 251-261.

Marchetti, G. and C. Scali. 2000. "Use of modified relay techniques for the design of model-based controllers for chemical processes", Industrial Engineering Chemistry Research, 39, 3325-3334.

Mudi, R.K. and N.R. Pal. 1999. "A robust self-tuning scheme for PI- and PD-type fuzzy controllers", IEEE Transactions on Fuzzy Systems, 7, No. 1, 2-16.

O'Dwyer, A. 2003a. "PID compensation of time delayed processes: a full survey", Technical Report AOD-00-05, Version 3, School of Control Systems, Dublin Institute of Technology, Ireland (Feb).

O'Dwyer, A. 2003b. Handbook of PI and PID controller rules Imperial College Press, London, U.K.

Panagopoulos, H., K.J. Astrom and T. Hagglund. 2002. "Design of PID controllers based on constrained optimisation", IEE Proceedings - Control Theory and Applications, 149, No. 1, 32-39.

Poulin, E. and A. Pomerleau. 1999. "PI settings for integrating processes based on ultimate cycle information", IEEE Transactions on Control Systems Technology, 7, No. 4, 509511.

Prashanti, G. and M. Chidambaram. 2000. "Set-point weighted PID controllers for unstable systems", Journal of the Franklin Institute, 337, No. 2-3, 201-215.

Rivera, D.E. and K.S. Jun. 2000. "An integrated identification and control design methodology for multivariable process system applications", IEEE Control Systems Magazine, June, 25-37.

Robbins, L.A. 2002a. "Tune control loops for minimum variability", Chemical Engineering Progress, January, 68-70.

Robbins, L.A. 2002b. "Setpoint tuning method gives excellent response to load changes", Hydrocarbon Processing, September, 49-50.

Sbarbaro, D., J.P. Segovia, S. Alcozer and J. Gonzales. 2000. "Applications of radial basis network technology to process control", IEEE Transactions on Control Systems Technology, 8 , No. 1, 14-22. 
Seborg, D.E., T.F. Edgar and S.L. Shah. 1986. "Adaptive control strategies for process control: a survey", AIChE Journal, 32, 881-913.

Seki, H., M. Ogawa and M. Ohshima. 2001. "PID temperature control of an unstable gas-phase polyolefin reactor", Journal of Chemical Engineering of Japan, 34, No. 11, 1415-1422.

Shen, J.-C. 2000. "New tuning method for PID control of a plant with under-damped response", Asian Journal of Control, 2, No. 1, 31-41

Shen, J.-C. 2002. "New tuning method for PID controller", ISA Transactions, 41, 473-484.

Shinskey, F.G. 2001. "PID-deadtime control of distributed processes", Control Engineering Practice, 9, 1177-1183.

Shu, H. and Y. Pi. 2000. "PID neural networks for time-delay systems", Computers and Chemical Engineering, Vol. 24, 859-862.

Sung, S.W., T.-Y. Lee and S. Park. 2002. "Optimal PID controller tuning method for single-input/single-output processes", AIChE Journal, 48, No. 6, 1358-1361.

Tan, K.K., Q.G. Wang, C.C. Hang and T.J. Hagglund. 1999. Advances in PID control, Advances in Industrial Control Series, Springer-Verlag London.

Tan, K.K., T.H. Lee and X. Jiang. 2000. "Robust on-line relay automatic tuning of PID control systems", ISA Transactions, 39, No. 2, 219-232.

Tan, K.K., T.H. Lee and X. Jiang. 2001. "On-line relay identification, assessment and tuning of PID controller", Journal of Process Control, 11, pp. 483-496.

Tan, K.K., T.H. Lee, S.N. Huang and F.M. Leu. 2002. "PID control design based on a GPC approach", Industrial Engineering Chemistry Research, 41, 2013-2022.

Tan, W., J. Liu and P.K.S. Tam. 1998. "PID tuning based on loopshaping $\mathrm{H}_{\infty}$ control", IEE Proceedings - Control Theory and Applications, 145, No. 6, 485-490.

Tang, W., S.-J. Shi and M.-X. Wang. 2002. "Autotuning PID control for large time-delay processes and its application to paper basis weight control”, Industrial Engineering Chemistry Research, 41, 4318-4327.

Tao, C.W. and J.S. Taur. 2000. "Flexible complexity reduced PIDlike fuzzy controllers", IEEE Transactions on Systems, Man and Cybernetics - Part B: Cybernetics, 30, No. 4, 510-516.

Unar, M.A., D.J. Murray-Smith and S.F.A. Shah. 1996. "Design and tuning of fixed structure PID controllers: a survey", Technical Report CSC-96016, Centre for Systems and Control, University of Glasgow, http://www.mech.gla.ac.uk/Research/ Control/Publications/Reports.html.

Visioli, A. 1999. "Fuzzy logic based set-point weight tuning of PID controllers", IEEE Transactions on Systems, Man and Cybernetics - Part A: Systems and Humans, 29, No. 6, 587592.

Visioli, A. 2001a. "Optimal tuning of PID controllers for integral and unstable processes", IEE Proceedings - Control Theory and Applications, 148, No. 2, 180-184.

Visioli, A. 2001b. "Tuning of PID controllers with fuzzy logic", IEE Proceedings - Control Theory and Applications, 148, No. $1,1-8$.

Vrancic, D., Y. Peng and S. Strmcnik. 1999. "A new PID controller tuning method based on multiple integrations", Control Engineering Practice, 7, No. 5, 623-633.

Vrancic, D., S. Strmcnik and D. Juricic. 2001. "A magnitude optimum multiple integration tuning method for filtered PID controller", Automatica, 37, 1473-1479.
Wang, L., M.L. Desarmo and W.R. Cluett. 1999d. "Real-time estimation of process frequency response and step response from relay feedback experiments", Automatica, 35, 14271436.

Wang, L. and W.R. Cluett. 2000. From plant data to process control, Taylor and Francis Ltd.

Wang, Q.-G., T.-H. Lee, H.-W. Fung, Q. Bi and Y. Zhang. 1999a. "PID tuning for improved performance", IEEE Transactions on Control Systems Technology, 7, No. 4, 457-465.

Wang, Q-G., H.-W. Fung and Y. Zhang. 1999b. "PID tuning with exact gain and phase margins", ISA Transactions, 38, 243-249.

Wang, Q.-G., C.-C. Hang, S.-A. Zhu and Q. Bi. 1999c. "Implementation and testing of an advanced relay auto-tuner", Journal of Process Control, 9, No. 4, 291-300.

Wang, Q.-G., Y. Zhang and X. Guo. 2001a. "Robust closed-loop identification with application to auto-tuning", Journal of Process Control, 11, 519-530.

Wang, Q.-G., C.C. Hang and X.-P. Yang. 2001b. "Single-loop controller design via IMC principles", Automatica, 37, 20412048.

Wang, Y.-G. and W.-J. Cai. 2002. "Advanced proportional integral derivative tuning for integrating and unstable processes with gain and phase margin specifications", Industrial Engineering Chemistry Research, 41, 2910-2914.

Wilton, S.R. 1999. "Controller tuning”, ISA Transactions, 38, $157-170$.

Xu, J.-X., Y.-M. Pok, C. Liu and C.-C. Hang. 1998. "Tuning and analysis of a fuzzy PI controller based on gain and phase margins", IEEE Transactions on Systems, Man and Cybernetics - Part A: Systems and Humans, 28, 685-691.

Xu, J.-X., C.-C. Hang and C. Liu. 2000. "Parallel structure and tuning of a fuzzy PID controller", Automatica, 36, 673-684.

Yang, X.-P., Q.-C. Wang, C.C. Hang and C. Lin. 2002a. "IMCbased control system design for unstable processes", Industrial Engineering Chemistry Research, 41, 4288-4294.

Yang, Y.G. and H.-H. Shao. 2000a. "PID auto-tuner based on sensitivity specification", Transactions of the Institute of Chemical Engineers, 75, Part A, 312-316.

Yang, Y.-G. and H.-H. Shao. 2000b. "Optimal tuning for PI controller", Automatica, 36, 147-152.

Yang, Y.-S., Q.-G. Wang and W. Dai. 2002b. "Robust PID controller design for gain and phase margins", Journal of Chemical Engineering of Japan, 35, No. 9, 874-879.

$\mathrm{Yu}$, C.-C. 1999. Autotuning of PID controllers, Advances in Industrial Control Series, Springer-Verlag London Ltd.

Zhang, W., X. Xu and Y. Sun. 1999. "Quantitative performance design for integrating processes with time delay", Automatica, 35, 719-723.

Zhang, W. and X. Xu. 2000. "On the model reference method for unstable time delay systems". Computers and Chemical Engineering, 24, 2765-2766.

Zhang, W. and X. Xu. 2002. " $\mathrm{H}_{\infty}$ PID controller design for runaway processes with time delay", ISA Transactions, 41, 317-322.

Zhong, Q.-C. and H.-X. Li. 2002. "2-degree-of-freedom proportional-integral-derivative-type controller incorporating the Smith principle for processes with dead time", Industrial Engineering Chemistry Research, 41, 2448-2454.

Ziegler, J.G. and N.B. Nichols. 1942. "Optimum settings for automatic controllers", Transactions of the ASME, 64, 759768. 